\title{
CONSIDERAÇÕES ACERCA DA TEORIA DECOLONIAL POR MEIO DE REFLEXÕES SOBRE A PRÁTICA DOCENTE EM LÍNGUA INGLESA
}

\section{CONSIDERATIONS ON DECOLONIAL THEORY THROUGH REFLECTIONS ON ENGLISH TEACHING PRACTICE}

Selma Silva Bezerra'

\begin{abstract}
RESUMO: Com base em resultados da pesquisa autoetnográfica, este artigo tem como objetivo analisar práticas docentes de língua inglesa à luz da teoria decolonial (QUIJANO, 2005; 2007; GROSFOGUEL, 2007; MIGNOLO, 2007; MALDONADOTORRES, 2007), além de refletir sobre método e ensino de língua inglesa a partir de Kumaravadivelu (2003a; 2003b; 2016). Para tanto, apresento e discuto as premissas centrais do grupo Modernidade/Coloniadidade. Após, relaciono esses conceitos com o ensino de língua inglesa, focalizando as consideraçôes sobre método, defendidas por Kumaravadivelu (2003a; 2003b; 2016). Além disso, relaciono os conceitos debatidos às minhas práticas de sala de aula, apresentando meus dilemas e, consequentemente, os reflexos de colonialidades que permeiam minhas práticas.
\end{abstract}

PALAVRAS-CHAVE: Decolonialidade. Prática docente. Ensino de inglês.

ABSTRACT: Based on the outcomes of an autoethnography research, this paper aims at analyzing my teaching praxis in the light of decolonial theory (QUIJANO, 2005; 2007; GROSFOGUEL, 2007; MIGNOLO, 2007; MALDONADO-TORRES, 2007) and reflecting on method and English language teaching based on Kumaravadivelu (2003a; 2003b; 2016). In order to achieve this purpose, some of the main premises of the Modernity/Coloniality group are related to the English language teaching, based on Kumaravadivelu's (2003a; 2003b; 2016) discussion about methods. Furthermore, my praxis is related to those concepts, reflecting on my dilemmas and, consequently, on the traces of coloniality that encompassed my teaching practices.

KEYWORDS: Decoloniality. Teaching practice. English teaching.

\section{INTRODUÇÃO}

Este artigo visa a analisar minha prática docente de língua inglesa à luz da teoria decolonial. $\mathrm{O}$ estudo ${ }^{2}$ foi desenvolvido em uma instituiçâo pública de ensino, com

1 Instituto Federal de Educaçăo, Ciência e Tecnologia de Alagoas (IFAL).E-mail: selma.bezerra@hotmail.com

20 artigo é um recorte de minha tese de doutorado desenvolvida no Programa de Pós-Graduaçăo em Letras e Linguística da Universidade Federal de Alagoas (UFAL). A pesquisa foi aprovada pelo Comitê de Ética da universidade. O número do parecer de aprovaçăo é 2.025.937. 
alunas/os do $1^{\circ}$ ano do Ensino Médio integrado ao curso de Agropecuária. A pesquisa ocorreu entre junho e dezembro de 2017, durante um semestre letivo, na disciplina de Língua Inglesa I, cuja turma comportava alunos de faixa etária entre 14 (quatorze) e 18 (dezoito) anos. Nessa perspectiva, narro algumas das experiências vividas com a turma, as quais, no decorrer do trabalho, săo fundamentadas com os pressupostos teóricos do grupo Modernidade/Colonialidade, que advoga o conceito de decolonialidade como forma de buscar outros padróes de vida, de modo a repensar os padróes eurocêntricos. Além disso, busco aporte teórico em Kumaravadivelu (2003a; 2003b; 2016), o qual defende a necessidade do desenvolvimento de uma alternativa aos métodos de ensino de língua inglesa.

Tendo em vista que questóes pessoais sâo políticas (JONES, 2005 apud DUTTA; BASU, 2013), uma vez que, como um ser político, minhas escolhas săo também políticas e revelam minha visăo de sala de aula, de linguagem e de mundo, esta pesquisa se insere na perspectiva autoetnográfica, a qual investiga as experiências de vida e cultura do sujeito, para que, por meio delas, seja possível criar reflexóes nas quais investigador e investigaçâo se confundem. Desse modo, as experiências vivenciadas em minha turma tornam-se objetos de interpretaçăo, as quais servem como suporte inicial para reflexóes que me orientam como professora e pesquisadora. Assim, narro meu percurso de pesquisa, revisitando as experiências que contribuíram para que eu repensasse e reconstruísse o fazer docente em abordagem autoetnográfica.

Diante disso, o artigo está dividido em duas seçōes: (1) pensamento decolonial, visando a explanar seus principais conceitos; e (2) práticas colonizadoras e práticas decoloniais, enfatizando questionamentos e dilemas de pesquisa em articulaçấo com os conceitos do grupo Modernidade/Colonialidade.

\section{PENSAMENTO DECOLONIAL}

As tirinhas de Quino (1999) levaram-me a refletir sobre a imposiçăo da existência de um norte (que está acima) e de um sul (que está abaixo), demarcados geograficamente e politicamente, apesar de o planeta ser um globo. Esse fato náo possibilitaria uma descriçâo que determinasse quem está acima ou quem está abaixo, pois, a depender do ponto de vista (do olhar), é que a conclusăo é viabilizada. Como diria Saussure (1990), o ponto de vista cria o objeto. Assim, proponho-me a indagar: o que é norte? E o que é sul? $\mathrm{O}$ que determinou que o sul fosse sul e que o norte fosse norte? Como isso se deu, se todos os seres do planeta Terra vivem em um mesmo globo? 
Figura 1 - Tirinhas da Mafalda
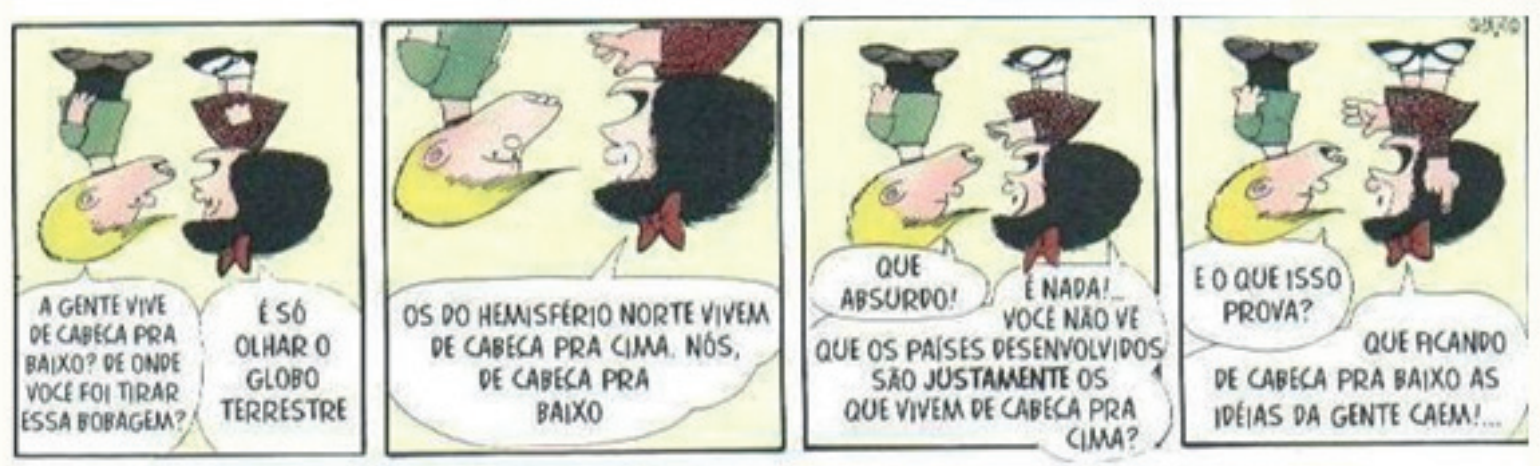

Fonte: Quino (1999)

Com base nessas questóes, é importante atentar para o fato de que as citadas tirinhas direcionam o entendimento de que năo há sul nem norte. O que ocorre, na verdade, é uma autonomeaçấo de alguém que se diz estar no norte e do outro que está no sul. Assim, é atribuída ao norte a característica de melhor, pois está localizado acima; ao sul, é atribuída a qualidade de pior, uma vez que está abaixo. Há, inclusive, uma expressăo em português que significa "me dá uma orientaçăo", que é expressa como "me dá um norte".

Questionamentos como esse têm sido feitos pela teoria decolonial quando propóe o giro decolonial. Giro decolonial é uma terminologia desenvolvida por Maldonado-Torres (2007) para designar a proposta teórica e política criada por um grupo de pensadores ${ }^{3}$, prioritariamente advindos do hemisfério sul, que se propóem a buscar por outra episteme para a vida e para a ciência. O grupo Modernidade/Colonialidade, como tem sido chamado, formula seu pensamento a partir do descobrimento das Américas até os dias atuais, apresentando uma crítica às principais teorias políticas e filosóficas de base eurocêntricas. Grosfoguel (2007), Quijano (2005; 2007) e Mignolo (2007) defendem que os conhecimentos acadêmicos e as formas de produçăo desses conhecimentos foram criados a partir de ideais colonialistas e eurocêntricas, por isso a necessidade da existência de uma alternativa, ou seja, outra forma de pensar a sociedade e seus padrōes.

Para Ballestrin (2013, p. 105), o giro decolonial "significa o movimento de resistência teórico e prático, político e epistemológico, à lógica da modernidade/colonialidade". Trata-se da busca por outras ontologias sobre quem somos, onde vivemos e o que queremos para o nosso futuro. Esses teóricos me fizeram questionar a respeito dos modos de vida e os artefatos culturais da nossa sociedade que geralmente seguem preceitos e padrôes náo estabelecidos por nós, povos de Abya Yala ${ }^{4}$. Por isso, a

3 O grupo Modernidade/Colonialidade, que propōe o giro decolonial, é formado por Aníbal Quijano, Enrique Dussel, Walter Mignolo, Immanuel Wallerstein, Santiago Castro-Gómez, Nelson Maldonado-Torres, Ramón Grosfoguel, Edgardo Lender, Arthuro Escobar, Fernando Coronil, Catherine Walsh, Boaventura Souza Santos e Zulma Palermo.

4 Expressâo sinônima de América, é utilizada pelos povos originários para "construir um sentimento de unidade e pertencimento" (PORTO-GONÇALVES). Traz um caráter político e epistemológico, pois entende que os povos originários (povos indígenas) nomearam seus territórios, antes da invasấo dos europeus. Disponível em: http://latinoamericana.wiki.br/verbetes/a/abya-yala. Acesso em: 2 ago 2018. 
teoria decolonial propóe uma açâo de enfrentamento a esse outro colonial. Ela traz a proposiçấo de pensar a partir das fronteiras, das ruínas, sugerindo um olhar para si cuidadoso e investigativo na busca por outras visóes de si, que possam apontar para as nossas regionalidades e tradiçóes, como alternativas ao pensamento eurocêntrico. 0 termo decolonial, portanto, remete ao processo pelo qual os autores do sul ratificam a defesa de outra episteme. Assim, é a proposta de uma alternativa à organizaçăo do conhecimento de bases eurocêntricas. Nessa perspectiva, Walsh (2009) explica que envolve um movimento de reconstruçâo de uma ordem local de vida e de conhecimento. Essa autora enfatiza que a decolonialidade é "uma postura ofensiva de intervençăo, transgressăo e reconstruçăo" (WALSH, 2009, p. 234). Desse modo, náo é um novo padrầo a ser imposto, mas uma ofensiva que busca a viabilizaçăo e a visualizaçấo de conceitos, práticas e modos de viver, ser, estar e pensar, abrindo espaço para o ensino, para a desaprendizagem e para a reflexâo (WALSH, 2009).

Nessa direçăo, Ballestrin (2013, p. 108) enfatiza que "a supressâo da letra 's' marcaria a distinçăo entre o projeto decolonial do grupo Modernidade/Colonialidade e a ideia histórica de descolonizaçấo, via libertaçâo nacional durante a Guerra Fria". Desse modo, a descolonizaçáo seria uma forma de superar as amarras coloniais que ainda estâo em vigência. Sendo assim, Walsh (2009) esclarece que o prefixo "des" remete às ideias de transiçăo, de superaçâo e de emancipaçâo e, neste caso específico, com relaçăo à história, à política local e residual. Diante dessa diferença, creio que a decolonialidade é a luta para que outras epistemologias possam ter visibilidade, acesso e espaço, uma vez que năo há como apagar o passado de colonizaçăo epistemológica e ontológica que os povos de Abya Yala viveram. Entendo, por se tratar de algo recente na LA, que alguns autores, como Kleiman (2013), năo fazem essa distinçăo, mas acredito ser importante que essa diferença seja marcada. Por isso, utilizo a nomenclatura decolonialidade, pois é a terminologia defendida pelo grupo, apesar de alguns autores com quem dialogo fazerem uso dos dois termos: decolonialidade e descolonialidade, indistintamente.

Desse modo, o pensamento decolonial, proposto pelo grupo Modernidade/ Colonialidade, refere-se a uma quebra epistêmica que busca uma diferença, ou seja, a formaçăo de outra postura teórica em relaçăo à construçăo do conhecimento, às formas de vida e ao padrâo científico. Para Mignolo (2007),

o giro decolonial é a abertura e a liberdade de pensamento e de outras formas de vida (outras economias, outras teorias políticas); a limpeza da colonialidade do ser e do saber; o desprendimento da retórica e da modernidade e de seu imaginário imperial articulado na retórica da democracia (MIGNOLO, 2007, p. 29-30).

A partir dessa visâo, o giro decolonial relaciona-se à criaçăo de racionalidades outras que náo apresentem somente o modelo eurocentrado, mas que proporcionem espaço para outras epistemologias. Dessa maneira, o giro decolonial é uma postura teórica que questiona as ontologias dos povos de Abya Ayla, propiciando um repensar de quem sou, do que pretendo ser e de como posso atuar dentro e fora das minhas salas de aula. É, pois, uma atitude de vida pessoal e profissional. Na seçăo que segue, exponho o relato da experiência de pesquisa com a turma escolhida, ressaltando que meu objetivo era compreender o processo, a fim de problematizar minha prática de ensino. 


\section{PRÁTICAS COLONIZADORAS E PRÁTICAS DECOLONIAIS}

Como a instituiçăo em que esta pesquisa se desenvolveu năo apresentava orientaçôes pré-estabelecidas para as aulas, eu tinha abertura para prepará-las sem conteúdos pré-agendados. Assim, logo após o início das aulas, pedi que os alunos e as alunas respondessem a um questionário, e, a partir disso, observei como sugestâo a introduçáo de cançôes. Entretanto, minha experiência me mostrou que uma postura centralizadora nâo funciona: eu impunha, sem me dar conta, o estilo musical e as temáticas com as quais eu me identificava. Essa prática individualizada e centrada pode ser vista como um efeito de minha formaçăo, que teve como fonte as teorias construídas em outras localidades, principalmente no Norte.

Embora a adoçâo de métodos nâo fosse a realidade do curso de ensino médio integrado no qual atuo, compreendo que os princípios que utilizava em sala de aula eram orientados pelos métodos que estudei e tive contato durante minha formaçăo: mesmo nâo adotando métodos explicitamente, eu sentia que minha prática era influenciada por eles. Sobre esse assunto, Kumaravadivelu (2003a; 2003b; 2016) explica que os métodos de ensino de línguas sâo construçôes coloniais, considerando que possuem características coloniais dominantes, mesmo quando săo adaptados. No dizer do autor, o método tem caráter de marginalidade, uma vez que toma o colonizador e seus conhecimentos como superiores, e o colonizado como inferior e incapaz. Traduzindo para as palavras do grupo Modernidade/Colonialidade, os métodos sâo veículos da racionalidade eurocêntrica.

Em minhas aulas em geral (com métodos ou náo), os passos em sala de aula eram feitos de cima para baixo ou partiam de mim. Eu acreditava que era somente minha a responsabilidade de decidir e avaliar o que era necessário ser feito. Hoje, percebo que minha prática docente, influenciada por métodos de ensino de línguas, sofria, ao mesmo tempo, a atuaçâo das forças da colonialidade, ou seja, ao investigar minha prática docente, penso que uma possibilidade de interpretaçáo é a de que, ao determinar conteúdos e atividades, eu ditava visóes sobre o mundo e escolhas pessoais. Devido a isso, observo que minha prática se aproximava, de certo modo, da prática do colonizador, na qual somente o seu modo de ser era tido como válido, apresentado como superior ao colonizado, o que lhe garantia o direito de impor suas práticas de vida, como religiâo, cultura e valores. Nessa perspectiva, náo havia espaço para as/os alunas/alunos nos meus planos de aula. Certamente, eu nâo me dava conta da exclusăo que gerava. Além disso, é como se eu, professora, fosse detentora do poder superior em sala de aula e que isso bastava para que eu pudesse dizer como os outros aprendem e quando aprendem.

Após essas primeiras percepçōes das aulas, almejava, entăo, romper com essa prática centralizadora e colonial. Por isso, minha atitude, naquele momento, foi a de definir com a turma a escolha da cançáo a ser trabalhada, o que se fez muito importante para mim. Ademais, minha preocupaçăo era a de como trabalhar com as cançôes, já que eu nâo poderia escolhê-las, mas deixar a turma escolher. Tal atitude, a meu ver, pode se configurar como uma prática de decolonialidade, uma vez que rompe com a normativa em que coloca o professor como o responsável por todas as decisóes em sala de aula.

Antes de pensar em como trabalhar as cançóes, senti como primeira dificuldade o compartilhamento das decisóes com a turma sobre os conteúdos trabalhados em sala. Essa dificuldade demonstra meu receio de perder o controle (poder) sobre os conteúdos 
e sobre o desenvolvimento das aulas. Eu, professora, necessitava manter as rédeas sempre apertadas para me sentir segura. Como poderia deixar que as aulas fossem conduzidas por cançóes escolhidas pelos/as alunos/as/participantes? Aproveito este momento para retornar à questâo e reforçar o entendimento que tinha da necessidade de controle sobre o material e conteúdos em sala para poder afirmar que tal fato partiu, entre outras questóes, do desejo de um planejamento fixo que me possibilitasse o "domínio" da língua inglesa. Desse modo, mais uma vez, a vontade do controle dos conteúdos é o que pode se configurar como um efeito da colonialidade na minha prática. Apesar desse efeito, tive que colocar minha insegurança de lado e encarar o desafio de năo ter o controle da aula sob as minhas rédeas. Decidi, dessa forma, dividir esse controle e essa responsabilidade com os/as alunos/as, ou seja, compartilhar, com eles/ as, as escolhas sobre cada passo que seria dado em sala, para construir um processo mais participativo.

No decorrer das aulas, o barulho, decorrente de atividades realizadas em grupo, ou mesmo resultante de conversas paralelas, me causava certo desconforto. No excerto abaixo, ao escrever, em meu diário reflexivo, sobre como o barulho em sala de aula me incomodava, já inicio uma reflexăo sobre o porquê dessa minha insatisfaçăo. No momento, acredito que o motivo para esse incômodo se deveu ao fato de minha atuaçâo sofrer os efeitos da colonialidade. Será que mais uma vez adotei a postura da professora que quer ter o controle de tudo?

Entăo, fiquei muito feliz ao perceber que estavam praticando, inclusive o Severino sempre tentava falar o que aprende, mas meu moralismo de professora que tem que manter o controle soou mais alto. Mesmo entendendo que manter o controle é também manter o poder em sala de aula, năo consegui me libertar dessa tradiçăo. Por isso, devo pensar mais antes de interromper os/as alunos/as, refletir mais ainda sobre minha prática, pois se pretendo ressignificá-la, tenho que reaprender a ensinar. De certo modo, năo sei se estou completamente errada, mas acho que preciso aprofundar a reflexáo de cada ato mínimo que acontecer em sala de aula. (Diário reflexivo - 07/6/ 2017)

A primeira ponderaçâo a esse respeito relaciona-se à minha experiência como aluna. Lembro-me que, quando um/a professor/a entrava na sala e todos/as se calavam para o/a escutar, o silêncio absoluto, aparentemente, reinava, e todos/as prestavam atençăo. Eu, naquela época, entendia que esse/a professor/a era um/a bom/boa profissional. Percebo que eu reproduzia esse modelo quando ministrava minhas aulas. A segunda reflexăo refere-se ao controle, que poderia estar relacionado à visăo colonial de ensino a qual tenta encaixar os profissionais em um mesmo modus operandi, ou seja, enquadra o/a professor/a em um método específico e o/a coloca em uma posiçáo de poder absoluto em sala. Entendo, assim, que era como se eu quisesse me enquadrar em um paradigma, às vezes até imaginário, pois o silêncio absoluto nunca existiu e nem nunca vai existir. No entanto, como escrevi no diário, para ressignificar minha prática, para reaprender, eu tinha que repensar a ânsia por manter o controle, que agora vejo como um resquício da formaçăo e da minha história de vida que perpassaram os minha prática como professora.

Diante desse afâ por silêncio, por controle, por encaixar-me em determinada prática, me pergunto o que isso pode significar. Assim, dentre as várias possibilidades de 
interpretaçăo, atrelo esse anseio a uma terceira reflexăo sobre minha visăo de ensino: um modo de prever que todos/as aprendem com o silêncio, com o controle e com práticas repetidas. Isso pode demonstrar a vontade por um ensino que se caracteriza pelo foco em conteúdos, no qual o/a professor/a é tido como dono/a da verdade, que deve falar e cujas/os alunas/os devem escutar, ou seja, um sistema de ensino em que nâo há trocas, em que todas/os săo tratadas/os do mesmo modo para obter as mesmas produçóes. Isso pode corroborar outro conceito do grupo Modernidade/Colonialidade: a noçăo de colonialidade do poder, desenvolvida por Quijano $(2005 ; 2007)$ e que está relacionada ao controle das forças políticas e econômicas por parte dos grandes centros para a manutençáo do poder global e, ao mesmo tempo, local. Desse modo, a colonialidade do poder traz consequências diretas para minha vida, sem que eu mesma perceba. Uma delas pode ser em relaçăo ao modo como entendo o ensino, pautado pelo silêncio, pelo controle, a serviço da manutençăo dos sistemas que sustentam injustiças e exclusôes sociais entre aquelas/es que sâo autorizadas/os a falar e aquelas/es que devem ouvir, entre aquelas/es que produzem conhecimento e aquelas/es que consomem tal conhecimento.

Essas reflexóes me serviram (e ainda me servem) de sinal para que eu continue a questionar minha prática de sala de aula e o ensino de língua inglesa.

\title{
CONSIDERAÇÕES FINAIS
}

Diante das reflexóes apresentadas, registro que, como professora, enxergo-me em processo de amadurecimento teórico e prático sobre minha profissâo, o qual vem me possibilitando refletir sobre as colonialidades de meu fazer docente. Com esse entendimento, sigo pontuando ainda mais inquietaçôes sobre minha prática. Para finalizar, registro um poema que escrevi durante a conduçăo da pesquisa.

\section{Binarismos da minha prática}

\author{
Velha ou nova \\ EM PROCESSO \\ Início ou fim \\ EM TRÂNSITO
}

Melhor ou pior

REFLETINDO

Repetindo ou inovando

QUESTIONANDO 


\section{REFERÊNCIAS}

BALLESTRIN, L. América Latina e o giro decolonial. Revista Brasileira de Ciência Política, n. 11, p. 89-117, 2013.

DUTTA, M. J.; BASU, A. Negotiating our postcolonial selves: from the ground to the Ivory tower. In: ADAMS, T. E.; ELLIS, C.; JONES, S. H. (Org.). Handbook of autoethnography. Nova York: Routledge, 2013. p. 143-161.

GROSFOGUEL, R. Dilemas dos estudos étnicos norte-americanos: multiculturalismo identitário, colonizaçăo disciplinar e epistemologias descoloniais. Ciência e Cultura, v. 59, n. 2, p. 32-35, 2007.

KLEIMAN, A. B. Agenda de pesquisa e açăo em Linguística Aplicada: problematizaçóes. In: MOITA LOPES, L. P. (Org.). Linguística Aplicada na modernidade recente: festschirift para Antonieta Celani. Sáo Paulo: Parábola, 2013. p. 39-58.

KUMARAVADIVELU, B. Critical Language Pedagogy: a postmethod perspective on english language teaching. Word Englishes, v. 22, n. 4, p. 539-550, 2003 a.

KUMARAVADIVELU, B. Beyond Methods: macrostrategies for language teaching. New Haven: Yale University Press, 2003b.

KUMARAVADIVELU, B. The decolonial option in English Teaching: can the subaltern act? Tesol Quartely, v. 50, n. 1, p. 66-85, 2016.

MALDONADO-TORRES, N. Sobre la colonialidad del ser: contribuiciones al desarrollo de un concepto. In: CASTRO-GOMEZ, S.; GROSFOGUEL, R. (Ed.). El giro decolonial: reflexiones para una diversidad espistémica más alládel capitalismo global. Bogotá: Siglo del Hombre; Universidad Central, Instituto de Estudios Sociales Contemporáneos y Pontificia Universidad Javeriana, Instituto Pensar, 2007, p. 127-167.

MIGNOLO, W. El pensamiento decolonial: desprendimiento y apertura. un manifesto. In: CASTRO-GÓMEZ, S.; GROSFOGUEL, R. (Ed.). El giro decolonial: reflexiones para una diversidad espistémica más alládel capitalismo global. Bogotá: Siglo del Hombre; Universidad Central, Instituto de Estudios Sociales Contemporáneos y Pontificia Universidad Javeriana, Instituto Pensar, 2007, p. 25-46.

PORTO-GONCALVES, C. W. Abya Yala. Disponível em http://latinoamericana.wiki. br/verbetes/a/abya-yala. Acesso em: 5 ago 2018. 
QUINO . Toda Mafalda. Martins Fontes, 1999.

QUIJANO, A. Colonialidade do porder, eurocentrismo e América Latina. In: LANDER, E. (Org.). A colonialidade do saber: eurocentrismo e ciências sociais. Perspectivas latino americanas. Buenos Aires: CLACSO, 2005, p. 107-130.

QUIJANO, A. Colonialidaddel poder y clasificación social. In: CASTRO-GOMEZ, S.; GROSFOGUEL, R. (Ed.). El giro decolonial: reflexiones para una diversidad espistémica más alládel capitalismo global. Bogotá: Siglo del Hombre; Universidad Central, Instituto de Estudios Sociales Contemporáneos y Pontificia Universidad Javeriana, Instituto Pensar, 2007, p. 93-126.

SAUSSURE, F. Curso de Lingüística Geral. Sāo Paulo: Cultrix, 1990.

WALSH, C. Interculturalidad, estado, sociedad: luchas (de)coliniales de nuestra época. Quito: Abya-Yala, 2009. 